\section{Fatal myocardial damage due to zinc phosphide intentional ingestion}

\author{
Francesco Marino, ${ }^{1}$ Massimo Salvetti, ${ }^{1}$ \\ Abramo Bazza, ${ }^{1}$ Mara Rossi, ${ }^{2}$ \\ Maria Lorenza Muiesan' \\ 'Department of Clinical and Experimental \\ Sciences, University of Brescia; \\ 2Department of Internal Medicine, \\ Spedali Civili General Hospital, Brescia, \\ Italy
}

\section{Abstract}

We present a case of fatal myocardial damage caused by zinc phosphide ingestion. It is a highly toxic poison that causes life-threatening complications (cardiac and respiratory acute failure above all) by its active metabolite phosphine. Phosphine toxicity's case reports from Europe (and Italy), United States and western countries are rare. A 69-year-old man drunk a great amount of alcohol and unspecified amount of diluted zinc phosphide and was admitted to emergency department with a mild metabolic acidosis and acute respiratory failure. After gastro-intestinal decontamination, a transient improvement of his clinical conditions was observed. In the emergency medicine unit a sudden onset of severe bradycardia and hypotension appeared, electrocardiogram showed an increase in QRS duration with STelevation in many leads; 2 min later a thirddegree atrio-ventricular block was evident. Bradycardia went into asystole and the patient had cardiac arrest. Despite all resuscitative maneuvers, $6 \mathrm{~h}$ after zinc phosphide ingestion the patient died. No antidote or specific therapy or management of this potentially lifethreatening poison are actually available, but only supportive and resuscitative measures.

\section{Introduction}

Zinc phosphide $\left(\mathrm{Zn}_{3} \mathrm{P}_{2}\right)$ is a non-anticoagulant rodenticide, worldwide available, used to control a variety of small mammal species. ${ }^{1,2}$ The prevalence of phosphides' fatal poisonings (accidental or intentional) is higher in Asia, in particular in the Indian Sub-Continent, while case reports from Europe (and Italy), United States and western countries are rare. ${ }^{3-5}$

After interaction with water or acid (ideal pH 2-4), its active metabolite phosphine (phosphorus trihydride - $2 \mathrm{PH}_{3}$ ) is released. The phosphine's making from zinc phosphide is the following:

$$
\begin{gathered}
\mathrm{Zn}_{3} \mathrm{P}_{2}+6 \mathrm{H}_{2} \mathrm{O} \rightarrow 3 \mathrm{Zn}(\mathrm{OH})_{2}+2 \mathrm{PH}_{3} \\
\mathrm{Zn}_{3} \mathrm{P}_{2}+6 \mathrm{H}^{+} \rightarrow 3 \mathrm{Zn}^{2+}+2 \mathrm{PH}_{3}
\end{gathered}
$$

Once absorbed through gastro-intestinal and respiratory tissue, phosphine rapidly alters mitochondrial morphology and function (disrupting mitochondrial networks, inducing the formation of circular vescicles and lowering mithocondrial membrane potential), inhibits oxidative respiration and may interact with hydrogen peroxide to form the highly reactive hydroxyl radical, causing the failure of cellular respiration and lipid peroxidation.

The major lethal consequence of phosphide ingestion, i.e. profound circulatory collapse, may be secondary to direct effects on cardiac myocytes, fluid loss and adrenal gland damage. A direct corrosive actions on gastric and respiratory mucosa has been also demonstrated for phosphides and phosphine.

The main target organs of phosphine toxicity are lungs, cardiovascular, gastro-intestinal and endocrine-methabolic systems, with a wide range of effects. ${ }^{3-11}$ We describe a case of zinc phosphide poisoning admitted to our emergency medicine unit (EMU).

\section{Case Report}

A 69-year-old man, with type 2 diabetes, ischemic heart disease, a bipolar disorder, chronic alcohol abuse and previous suicide attempts, drunk a great amount of alcoholics (2 liters of wine) and unspecified amount of diluted zinc phosphide powder after an argue with his wife. After $1 \mathrm{~h}$ he was admitted to the emergency department (ED).

At admission he was lethargic, confused, with a Glasgow Coma Scale score of 15/15; physical examination showed hypotension [blood pressure (BP) $80 / 40 \mathrm{mmHg}$ ], a normal heart rate $(60 \mathrm{bpm})$, oxygen saturation $98 \%$ with 02 by standard mask at 3 liters/min.; cardiac, thoracic and abdominal physical examination were normal. The first electrocardiogram showed sinus rhythm, no ST-T alterations and a first degree atrio-ventricular block (PR $0.21 \mathrm{~s}$ )

Arterial blood gas analysis (without 02 therapy) revealed a mild metabolic acidosis and acute respiratory failure $(\mathrm{pH} 7.3 \mathrm{pCO} 233 \mathrm{p02}$ $51 \mathrm{mmHg}$ HCO3-17 meq/L $\mathrm{P} / \mathrm{F}=242)$; serum lactate was $4.9 \mathrm{mmol} / \mathrm{L}$ (normal test values $<1.2 \mathrm{mmol} / \mathrm{L}$ ); calculated anion gap was high (25 meq/L).

It was also found a slight elevation of hepatic enzymes (aspartate aminotransferase 107 IU/L, alanine aminotransferase $81 \mathrm{IU} / \mathrm{L}$ ). Blood alcohol concentration was $253 \mathrm{mg} / \mathrm{dL}$. Red and white blood cells, platelet count and troponin I were all within the normal range. Creatinine
Correspondence: Francesco Marino, Department of Clinical and Experimental Sciences, University of Brescia, viale Europa 11, 25123 Brescia, Italy. Tel. +39.339 .8904695 - Fax: +39.030 .29881$

E-mail: francescomarino1982@gmail.com

Key words: zinc phospide, phosphine, poisoning, myocardial damage.

Received for publication: 8 November 2013. Revision received: 11 January 2014.

Accepted for publication: 15 January 2014.

This work is licensed under a Creative Commons Attribution 3.0 License (by-nc 3.0)

(C) Copyright F. Marino et al., 2014

Licensee PAGEPress, Italy

Emergency Care Journal 2014; 10:2110

doi:10.4081/ecj.2014.2110

was $1 \mathrm{mg} / \mathrm{dL}$ (modification of diet in renal disease-estimated glomerular filtration rate of $79 \mathrm{~mL} / \mathrm{min} / 1.73 \mathrm{~m}^{2}$ ).

Routine blood toxicologic panel was negative for all other investigated substances and drugs.

After a first phone contact with the reference Poison Control Center in Pavia, Italy, the patient underwent a gastric lavage, administration of activated charcoal and gastro-intestinal decontamination by magnesium sulphate. Crystalloids and esomeprazole intravenously (IV) were also administered.

Esophagogastroduodenoscopy was not performed in ED because of the patient's lack of cooperation and was postponed. At admission to the EMU, 2 h later, the patient's haemodynamic and respiratory parameters improved: hypotension resolved (BP 120/60 $\mathrm{mmHg}$ ), heart rate was $60 \mathrm{bpm}$ and oxygen saturation $98 \%$ with 02 -therapy at $3 \mathrm{~L} / \mathrm{min}$.

The patient was less confused and lethargic; physical examination was still normal, with no abnormalities in cardiovascular or respiratory function. After one hour a sudden onset of severe bradycardia (37 bpm) and hypotension (BP $70 / 45 \mathrm{mmHg}$ ) was recorded at the monitor, followed by a rapid worsening of clinical conditions (loss of consciousness, bradypnea).

A complete 12-leads ECG showed an increase in QRS duration with ST-elevation in V1-V3, III and aVF, ST-depression in V4-V6, I and aVL leads; two minutes later a third-degree atrio-ventricular block was evident (Figures 1 and 2). In few seconds bradycardia went into asystole and the patient had cardiac arrest.

Cardiopulmonary resuscitation's manouvers started immediately and were repeated for 30 minutes, epinephrine IV was administered and defibrillation was performed after short appearance of ventricular fibrillation.

The Poison Control Center was contacted 


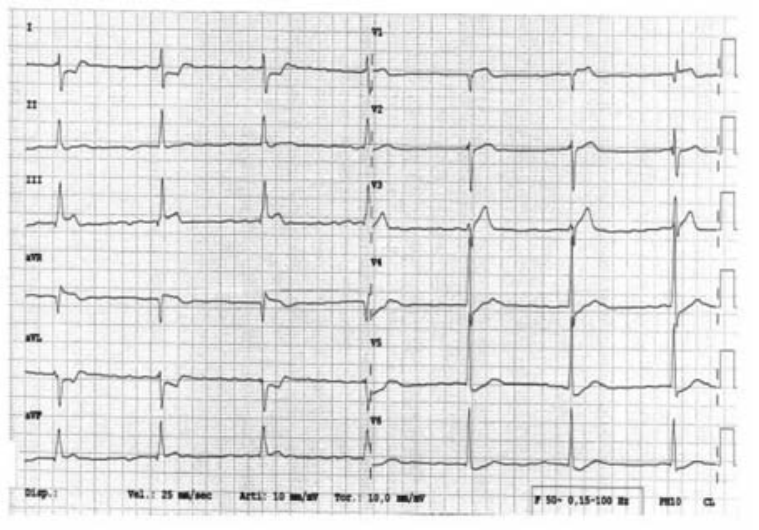

Figure 1. Patient's electrocardiography showing diffuse ST-T alterations.

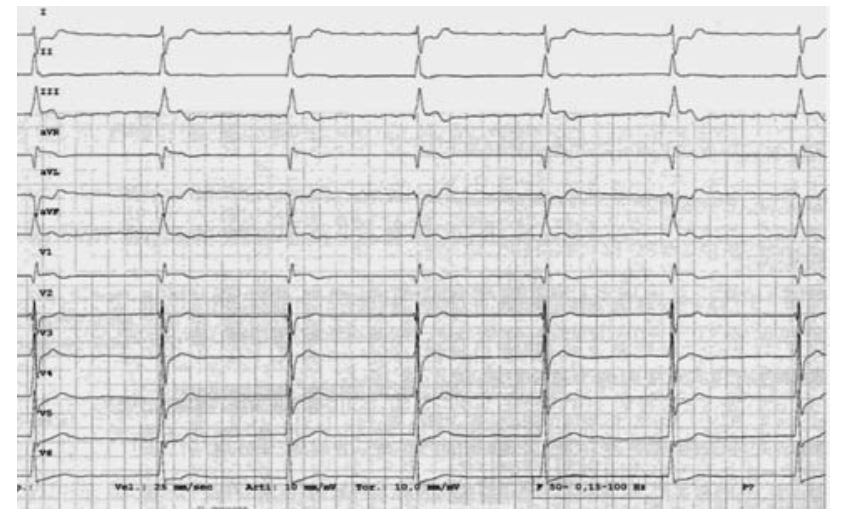

Figure 2. Patient's electrocardiography showing third-degree atrio-ventricular block. again and confirmed the lack of any known antidote against zinc phospide poisoning.

Despite all resuscitative maneuvers, $6 \mathrm{~h}$ after zinc phosphide ingestion the patient died.

\section{Discussion}

As we said above, phosphides' fatal poisonings have been rarely observed in Italy and Western Countries; however these substances are easily and widely available for different uses and there is little knowledge about their toxicity by occupational, accidental or intentional contact or ingestion.

Acute oral lethal doses for humans in literature and technical sheets range widely between 50 and $500 \mathrm{mg} / \mathrm{kg}^{1,4,11}$

In a prospective analysis of 20 patients with acute zinc phosphide poisoning, ${ }^{11}$ clinical signs and symptoms, including vomiting, restlessness and anxiety, palpitations and sweating, dyspnea, tachypnea, metabolic acidosis, hypotension, jaundice with hepatomegaly, pulmonary edema and shock were reported following a mean ingestion of $7.5 \mathrm{~g}$ (5-20 g). Five of the 20 patients died due to intractable shock, unresponsive to resuscitative measures. ${ }^{1,4,11}$

In our case the main phosphine's target was heart: probably there were involved a direct myocardial tissue damage and hypoperfusion, accelerated by the patient's pre-existent condition of coronary artery disease and the initial hypotensive state. Furthermore, the alcoholic acute intoxication, the mild metabolic acidosis and the acute respiratory failure may have promoted the onset of the irreversible and fatal myocardial damage. It cannot be excluded that a more complete and prolonged gastro-intestinal decontamination, by an early esophagogastroduodenoscopy, could have reduced the amount of absorbed phosphine and its deadly effect on the patient's heart.

Phosphine's toxicity on heart and lungs has been described in other few case reports, ${ }^{5,8,9}$ showing signs and symptoms of myocardial damage and severe respiratory failure, resulting in a fatal outcome despite an intensive management. $5,8,9$

Acute poisoning's clinical features have been so well described, even if it's only recently that the mechanisms of toxicity have been more clearly understood. ${ }^{4-11}$ Despite of this, the acute management is currently just supportive and mortality rate can reach high levels. ${ }^{1-11}$

\section{Conclusions}

Zinc phosphide is a highly toxic poison that causes life-threatening complications by its active metabolite phosphine $\left(2 \mathrm{PH}_{3}\right)$. No antidote or specific therapy or management of this potentially life-threatening poisoning are actually available. ${ }^{1-11}$

Supportive and resuscitative measures should be implemented as required by clinical findings and changes. ${ }^{1-9,12,13}$

In conclusion, despite prompt and supportive treatment, zinc phosphide poisoninginduced cardiac, respiratory and metabolic damages are associated with a high risk of death. Mortality rate can reach very high levels (range 37-100\%).

\section{References}

1. NPIC. Zinc phosphide/phosphine technical fact sheet - 2011. Corvallis, OR: National Pesticide Infomation Center, Oregon State University Publ.; 2011. Available from: http://npic.orst.edu/factsheets/znptech.pdf

2. NPIC. Rodenticides technical fact sheet 2011. Corvallis, OR: National Pesticide
Infomation Center, Oregon State University Publ.; 2011. Available from: http://npic.orst.edu/factsheets/rodenticides.pdf

3. Olson K. Poisoning and drug overdose. New York, NY; McGraw-Hill; 2011.

4. Proudfoot A. Aluminium and zinc phosphide poisoning. Clin Toxicol 2009;47:89-100.

5. Bogle RG, Theron P, Brooks $P$, et al. Aluminium phosphide poisoning. Emerg Med J 2006:23:e3.

6. Broderick M, Birnbaum K. Fatal ingestion of zinc phosphide rodenticide. J ToxicolClin Toxic 2002;40:684.

7. Ragone S, Bernstein J, Lew E, Weisman R. Fatal aluminum phosphide ingestion. J Toxicol-Clin Toxic 2002;40:690.

8. Shah V, Baxi S, Vyas T. Severe myocardial depression in a patient with aluminium phosphide poisoning: a clinical, ECG and histopathological correlation. Indian J Crit Care Med 2009;13:41-3.

9. Sogut 0, Baysal Z, Ozdemir B. Acute pulmonary edema and cardiac failure due to zinc phosphide ingestion. J Emerg Med 2011;40:117-8.

10. Zuryn S, Kuang J, Ebert P. Mitochondrial modulation of phosphine toxicity and resistance in caenorhabditis elegans. Toxicol Sci 2008;102:179-86.

11. Chugh SN, Haggarwal HK, Mahajan SK. Zinc phosphide intoxication symptoms: analysis of 20 cases. Int $\mathrm{J}$ Clin Pharm Th 1998;36:406-7.

12. Neumar RW, Otto CW, Link MS, et al. Adult advanced cardiovascular life support: 2010 AHA guidelines for cardiopulmonary resuscitation and emergency cardiovascular care. Circulation 2010;122:729-67.

13. Levine M, Brooks DE, Truitt CA, et al. Toxicology in the ICU. Part 1: general overview and approach to treatment. Chest 2011;140:795-806. 